\title{
Study of analyte stability time of serum electrolytes in a tertiary care public hospital
}

\author{
Dipti Tiwari ${ }^{*}$, Pramod Ingale², Shubhangi Wankhade ${ }^{3}$, M inal Pore $^{4}$
}

\begin{abstract}
${ }_{1}^{1}$ Assistant Professor, Department of Biochemistry, Grant Government M edical College and Sir JJ Gro up of Hospitals, M umbai, INDIA. 2Professor and HOD, 3 Speciality M edical Officer, 4 Speciality M edical Officer, Department of Biochemistry, Lo kmanya Tilak M unicipal M edical College, Sion, Mumbai, INDIA.
\end{abstract}

Email: tiwari.dipti02@gmail.com

\section{Abstract}

\begin{abstract}
Background: The collected and shipped blood samples are exposed to various extra-analytical factors prior to analysis. At times there is a delay in sample analysis after centrifugation due to a large sample load, breakdown of the analyzer and the nonavailability of a backup system. With this back ground we took up this study to see the effect of time on the assayed values of serum electrolytes. Material and Methods: We analyzed 152 samples for serum electrolytes at different time intervals between centrifugation and sample analysis on automated analyzer. The samples were received from different wards within one hour after sample collection. The samples were immediately analyzed after centrifugation and values recorded. The samples were kept in the lab uncovered as per the usual practice, with controlled environmental temperature conditions $\left(24 \pm 2^{\circ} \mathrm{C}\right)$ and were estimated twice after a gap of 2 hours each. i.e. at 3 hours and 5 hours post sample collection. All the samples were analyzed on the same instrument using Beckman AU680 analyzer on ISE mode. Results: Results compared using repeated measure ANOVA which showed statistical difference $\mathrm{P}<0.05$ between $1 \mathrm{st}$ and 2 nd, and 2 nd and 3rd measurement. There was statistically significant rise in values of $\mathrm{Na}$ and $\mathrm{K}$ over a period of time.Conclusion: Evaporation of sample could be the major cause leading to sample concentration resulting in high values. Simple measures like early analysis of samples or covering the samples properly will prevent such erroneous results.

Key Word: Sodium and Potassium, Electrolytes
\end{abstract}

*Address for Correspondence:

Dr. Dipti Tiwari, Assistant Professor, Department of Biochemistry, Grant Government Medical College and Sir JJ Group of Hospitals,

Mumbai, INDIA.

Email: tiwari.dipti02@gmail.com

Received Date: 30/01/2019 Revised Date: 01/03/2019 Accepted Date: 13/05/2019

DOI: https://doi.org/10.26611/10021031

\begin{tabular}{|l|l|}
\hline \multicolumn{2}{|c|}{ Access this article online } \\
\hline Quick Response Code: & Website: \\
\hline & www.medpulse.in \\
\cline { 2 - 2 } & \\
\hline
\end{tabular}

\section{INTRODUCTION}

Laboratory testing is a complex process which involves a series of interrelated steps and each step is prone to error. According to the draft of the ISO technical report 22367, laboratory error is defined as "a defect occurring at any part of the laboratory cycle, from ordering tests to reporting results and appropriately interpreting and reacting to these". . Laboratory error leads not only to unnecessary delays and additional costs by necessitating obligatory repeat samples but also imparts unnecessary pain to the patient. Laboratory testing is divided into three phases: preanalytical, analytical and post analytical. Most errors occur in the preanalytical phase (46-68.2\%) and the post analytical phase (18.5- 47\%) but still a large fraction (4$32 \%$ ) can be attributed to the intra analytical phase of the testing processii ${ }^{\text {ii }}$ Laboratory errors in the analytical phase have significantly decreased in recent times due to automation and technological advancements. The transition phase between the preanalytical and the intra analytical phase is also considered to be an important error prone area. Analyte stability time described by World Health Organization (WHO) ${ }^{\mathrm{iii}}$ and Clinical and laboratory Standard Institute (CLSI) ${ }^{\text {iv }}$ is often difficult to apply in the clinical settings as the time taken to transport samples from collection centre to laboratory and the time interval between centrifugation and processing are usually laboratory dependent variables.

Biochemical investigations routinely ordered by the clinicians are primarily blood glucose, liver function tests, kidney function tests and serum electrolytes. Electrolyte 
analysis includes sodium, potassium and chloride. $\mathrm{Na}^{+}$and $\mathrm{K}^{+}$form major cations of body fluids. $\mathrm{Na}^{+}$is the most abundant extracellular cation maintaining the osmolarity while $\mathrm{K}^{+}$is the most abundant intracellular cation maintaining the resting membrane potential and thus associated with conductivity of electrical impulse. Accurate estimation of serum electrolytes has gained importance in diagnosis of etiology of various diseases as it is used to calculate Anion Gap. Electrolyte abnormalities can precipitate life threatening events by derangements in its metabolic process or as a consequence of an underlying disease. Hyponatremia may be associated with sodium losses due to vomiting or diarrhea, diuretics abuse, salt losing nephropathy and osmotic diuresis, metabolic acidosis, adrenocortical insufficiency, dilution type hyponatremia may be due to edema, cardiac failure, hepatic failure and hypothyroidism. Hypernatremia is associated with conditions with water loss in excess of salt through profuse sweating, severe vomiting or diarrhea, diabetes insipidus or diabetic ketoacidosis, hyperaldosteronism, Cushing's syndrome, inadequate water intake because of coma or hypothalamic disease, dehydration or excessive saline therapy. Potassium plays a role in nerve conduction, muscle function and helps maintain acid-base balance and osmotic pressure. Measurement of serum potassium is used for evaluation of electrolyte imbalance, cardiac arrhythmia, muscular weakness, hepatic encephalopathy, monitoring of diabetic ketoacidosis and intravenous fluid replacement therapy. Electrolyte abnormalities are one of the common reversible causes of morbidity and mortality in Intensive Care Unit (ICU) patients $\mathrm{v}$. Analysis of these electrolytes dictate management protocol as well as outcome. There lies enough controversy regarding how quickly a serum sample has to be processed for them after collection. In a tertiary care set up, bulk samples are routinely received by the laboratory. Processing these samples therefore require sufficiently longer time periods and hence there are chances that the sample may deteriorate over a period of time giving inaccurate results. The development of blood collection tubes that contain gel and form a barrier after centrifugation has markedly improved serum analyte stability in the primary tube ${ }^{\text {vi,vii,viii }}$. There are few published studies on analyte stability in laboratories where there is a delay before centrifugation. Other studies have looked at the stability of various analytes in whole blood, however, the conditions to which the specimens were exposed have

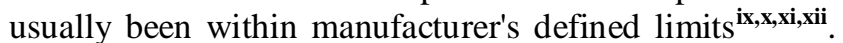
The Asia Pacific region has unique challenges arising from its vast geography and climatic conditions. Regional and remote health-care workers often do not have access to a centrifuge. This results in a delay of centrifugation and exposure of the specimen to variable temperatures and times during transport before being centrifuged ${ }^{\text {xiii. }}$.In majority of tertiary care hospitals, sample collection is done in the wards and the outpatient department by trained laboratory phlebotomists and are then transported to laboratory. The samples are then centrifuged and analysis is carried out using either standalone ISE analyzer or on fully automated clinical chemistry analyzer based on ISE method. Many a times there is a delay in sample analysis after centrifugation due to a large sample load, breakdown of the analyzer and the non-availability of a backup system. Hence variations in these electrolytes which do not correspond to the clinical state of the patient are commonly observed and repeat samples are required to be processed so as to get the reliable result. We therefore sought to evaluate the time lag between centrifugation and sample analysis which affect the stability of electrolytes in serum and find out the optimum time in which the samples need to be analyzed.

\section{AIMS AND OBJECTIVES}

1. To evaluate the variation in serum electrolyte $\left(\mathrm{Na}^{+}\right.$and $\left.\mathrm{K}^{+}\right)$levels due to delayed sample analysis.

2. To evaluate maximum acceptable delay time between sample collection and analysis.

\section{MATERIALS AND METHODS}

The study was conducted at Lokmanya Tilak Municipal Medical College, Sion, Mumbai. 152 samples collected from different wards were included in the study. Haemolysed, icteric and lipemic samples were excluded from the study. All samples were analyzed on the same instrument i.e. Beckman Coulter AU680 on ISE mode. Serum electrolyte values estimated immediately after centrifugation (within 1hour of sample collection) and then twice, after a gap of 2 hours each ( 3 and 5 hours post sample collection). Samples were kept uncovered in the lab as per the usual practice of the lab. Graph Pad prism was used for statistical analysis. Analysis of variance and paired-t test done on the values of serum electrolytes at three different time intervals.

\section{RESULTS}

Table. 1 shows a significantly $(\mathrm{p}<0.05)$ elevated serum sodium levels at $5 \mathrm{hrs}(152.67 \pm 7.1 \mathrm{meq} / \mathrm{L})$ as compared to $3 \mathrm{hrs}(145.27 \pm 5.3 \mathrm{meq} / \mathrm{L})$ and $1 \mathrm{hr}(139.08 \pm 4.1 \mathrm{meq} / \mathrm{L})$ respectively. We also observed significantly $(\mathrm{p}<0.05)$ increased levels of serum potassium levels at $5 \mathrm{hrs}(4.36 \pm$ $0.8 \mathrm{meq} / \mathrm{L})$ as compared to $3 \mathrm{hrs}(4.16 \pm 0.8 \mathrm{meq} / \mathrm{L})$ and $1 \mathrm{hr}$ $(3.98 \pm 0.8 \mathrm{meq} / \mathrm{L})$ respectively. 
Table 1: Comparison of Sodium and Potassium at different time intervals

\begin{tabular}{ccccccc}
\hline $\begin{array}{c}\text { Parameter } \\
\text { (meq/ L) }\end{array}$ & $\begin{array}{c}1 \text { hour } \\
\text { Mean } \pm \text { SD }\end{array}$ & $\begin{array}{c}\text { M houn } \pm \text { SD } \\
\text { Mean } \pm \text { SD }\end{array}$ & $\begin{array}{c}\text { Statistical } \\
\text { test }\end{array}$ & P value & \multirow{2}{*}{ Significance } \\
\hline Sodium & $139.08 \pm 4.1$ & $145.27 \pm 5.3$ & $152.67 \pm 7.1$ & ANOVA & $\varangle .0001$ & Significant \\
Potassium & $3.98 \pm 0.8$ & $4.16 \pm 0.8$ & $4.36 \pm 0.8$ & ANOVA & 0.0002 & Significant \\
\hline
\end{tabular}

*SD - Standard Deviation
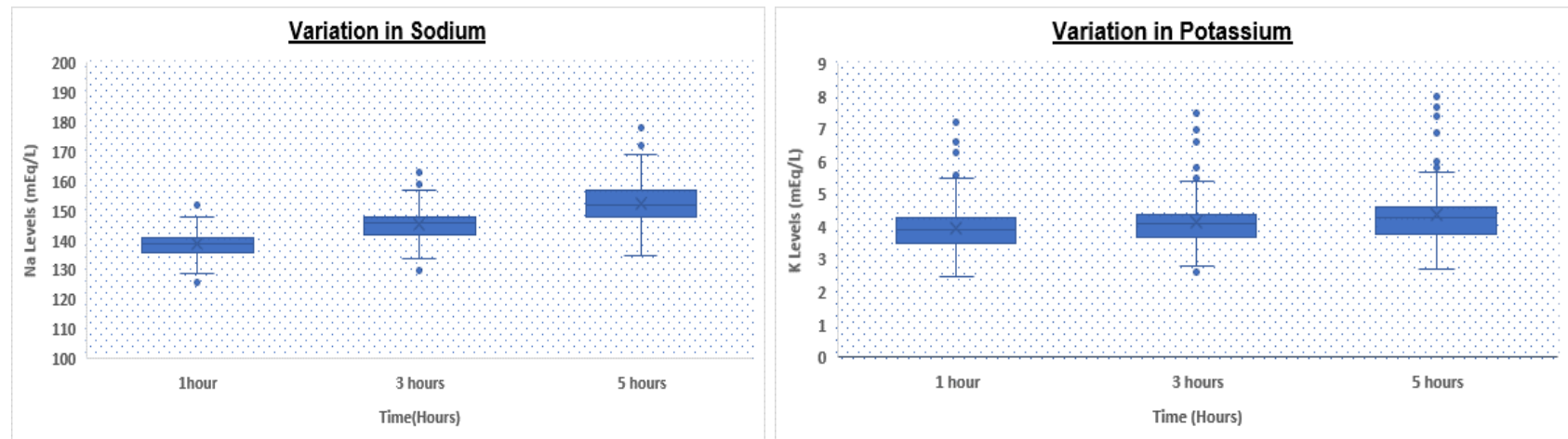

Box and Whisker Plot: Showing variation in So dium and Potassium levels

\section{DISCUSSION}

There was statistically significant rise in $\mathrm{Na}$ and $\mathrm{K}$ values ( $p$ value $<0.05$ ) over a period of time. Both analytes showed a significant difference at 3 hours and 5 hours with a $\mathrm{p}$ value of $<0.05$ for both. However, $\mathrm{K}$ values showed higher rise when analyzed after 5 hours of collection as compared to 3 hours while $\mathrm{Na}$ values increased with a higher rate during initial 3 hours as compared to 3-5 hours. Various studies have been conducted in the past to demonstrate the stability of many analytes. Donnelly et al, 1995 who investigated the stability of 25 analytes showed that $\mathrm{Na}$ and $\mathrm{K}$ remain stable for 24 at room temperature $4^{\circ} \mathrm{C}$ to $-20^{\circ} \mathrm{C}^{\text {xiv }}$. Boyanton et al, 2002, found that $\mathrm{Na}$ and $\mathrm{K}$ remain stable up to 56 hours $^{\mathbf{x v}}$. However, study by Tanner et al, 2008, on 35 analytes showed that stability of $\mathrm{K}$ is altered within 24 hours but sodium remains stable up to 24 hours. In all studies on analyte stability strict temperature maintenance is followed ${ }^{\mathbf{x i}}$. This gross difference between other stability studies and our study could be due to improper temperature maintenance and open sample tubes kept in laboratory leading to significant evaporation of samples. We are continuing the study further under strict temperature -controlled environment and capping all the tubes.

\section{CONCLUSION}

Evaporation of samples could be the major cause leading to concentration of samples resulting in high values. To conclude we suggest that the samples for measurement of serum electrolytes should be analyzed as soon as they are received in the laboratory preferably within 1-2 hour. In the event of any delay, sample cups should be properly covered and stored under proper environmental conditions to avoid erroneous results.

\section{REFERENCES}

1. P Bonini, M Plebani, F Ceriotti, F Rubboli. Errors in laboratory medicine. Clin Chem. 2002; 48: 691-98.

2. M Plebani. Errors in clinical laboratory or errors in laboratory medicine? Clin Chem Lab Med.2006;44(6):750-59.

3. Quality of diagnostic samples. Recommendations of the Working Group on Preanalytical Quality of the German Society for Clinical Chemistry and Laboratory Medicine. WHO/DIL/LAB. 2009:85.

4. Clinical and Laboratory Standards Institute (CLSI). Procedures for the handling and processing of blood specimens for common laboratory tests; approved guideline. Document Availablehttp://shopping.netsuite.com/c.1253739/site/Sa mple_pdf/H18-A4 2010.

5. CA Burtis, ER Ashwood, DE Bruns. Mitchell, Vicky and james. 4th Edition. 2006. Tietz textbook of clinical chemistry and molecular diagnostics; pp. 984-90

6. Boyanton BLBlick KE. Stability studies of twenty-four analytes in human plasma and serum. Clin Chem 2002; 48:2242-7

7. Heins M H, Withold W. Storage of serum or whole blood samples? effects of time and

8. Dousmas BT, Simuncak DM, Breitenfeld D. Differences between values for plasma and serum in tests performed in the Ektachem 700 AR Analyser, and evaluation of "plasma separator tubes (PST)". Clin Chem 1989; 35: 151-3.

9. Clark SY, Palmer A, Parish SP, Collins R. Stability of plasma analytes after delayed separation of whole blood: implications for epidemiological studies. Int J Epidemiol 2003; 32: 125-30.

10. Kitaguchi K, Takehara M, Shiiba M, Hayami K. Serumconstituents analyses: effect of duration and temperature of storage on clotted blood. Clin Chem1981; 27:35-8.

11. Rehak N, Chiang B. Storage of whole blood: effect of temperature on the measured concentration of analytes in serum. Clin Chem 1988;34: 2111-4. 
12. Zhang D, Elswick RK, Miller G, Bailey JL. Effect of serum-clot contact time on clinical chemistry laboratory results. Clin Chem 1998;44: 1325-33.

13. Tanner M, Kent N, Smith B, Fletcher S, Lewer M. Stability of common biochemical analytes in serum gel tubes subjected to various storage temperatures and times precentrifugation. Ann Clin Biochem. 2008 Jul;45(Pt 4):3759. doi:10.1258/acb.2007.007183. PubMed PMID: 18583622

14. Donnelly JG, Soldin SJ, Nealon DA, Hicks JM. Stability of twenty-five analytes in human serum at 22 degrees $\mathrm{C}, 4$ degrees C, and -20 degrees C. Pediatr Pathol Lab Med. $1995 ; 15(6): 869-74$.

15. Boyanton BL Jr, Blick KE. Stability studies of twenty-four analytes in human plasma and serum. Clin Chem. 2002;48(12):2242-7.

16. Tanner M, Kent N, Smith B, Fletcher S, Lewer M. Stability of common biochemical analytes in serum gel tubes subjected to various storage temperatures and times precentrifugation. Ann Clin Biochem. 2008 ;45(4):375-9.

\section{Source of Support: None Declared} Conflict of Interest: None Declared 